\title{
Distinct gestational trophoblastic neoplasia - different entities, specific management
}

\section{Pedro Brandão*, Juliana Silva-Rocha, Ana Rita Pinto, Fernanda Costa}

Department of Obstetrics and Gynaecology, Centro Hospitalar Tâmega e Sousa Av. Hospital Padre Américo 210, 4564-007 Penafiel, Porto, Portugal

Received: 25 November 2016

Accepted: 20 December 2016

\section{*Correspondence:}

Dr. Pedro Brandão,

E-mail: pedrobrandaoleite@gmail.com

Copyright: $\odot$ the author(s), publisher and licensee Medip Academy. This is an open-access article distributed under the terms of the Creative Commons Attribution Non-Commercial License, which permits unrestricted non-commercial use, distribution, and reproduction in any medium, provided the original work is properly cited.

\begin{abstract}
Gestational trophoblastic diseases are abnormalities of the trophoblastic tissue development. They have B-hCG as tumour marker, similar clinical manifestations but different pathological features, management and prognosis. Gestational trophoblastic neoplasia includes all forms of gestational trophoblastic disease that are invasive and/or metastasize and correspond to $10 \%$ of this group of diseases. The authors performed a retrospective review of all patients referred to our department between 1st January 2011 and $30^{\text {th }}$ June 2016. Presenting symptoms, B-hCG levels, obstetric and personal history and microscopic features were reviewed. 4 cases were identified - 2 invasive complete and 1 partial hydatidiform moles and 1 placental site trophoblastic tumour. Management and follow-up were individualized. Neither persistence nor recurrences were diagnosed after primary treatment. These case series highlights the importance of an accurate diagnosis and a long-term follow-up considering the risk of persistency or malignancy, as gestational trophoblastic neoplasia usually have good response to the adequate therapy.
\end{abstract}

Keywords: Gestational trophoblastic disease, Gestational trophoblastic neoplasia, Hydatidiform mole, Placental-site, Trophoblastic tumour

\section{INTRODUCTION}

\section{Epidemiology and risk factors}

Gestational trophoblastic disease (GTD) denominates a group of abnormalities of the trophoblastic tissue development. ${ }^{1}$ All of them arise from the trophoblastic epithelium of the placenta so they all have the beta subunit of human chorionic gonadothrophin (B-hGC) as tumour marker. However, these diseases have different pathological features, management and prognosis.

They can be divided in distinct groups: the abnormalities of the chorionic villi development, named hydatidiform moles, either complete (CHM) or partial (PHM) which may be persistent or invasive; and malignant tumours arising from different components of the trophoblastic tissue, namely choriocarcinoma (CC), placental site trophoblastic tumours (PSTT) and epithelioid trophoblastic tumour (ETT). ${ }^{1,2}$ Gestational trophoblastic neoplasia denominates the group of malignant entities, either invasive moles or other malignant tumours.

The prevalence of these diseases is around 1-3: 1000 pregnancies and about $90 \%$ of the cases are non invasive hydatidiform moles. ${ }^{2-4}$ Both PSTT and ETT are extremely rare.

The two main risk factors are extreme maternal ages (especially over 35) and history of previous GTD. 1,5 Smoking, nuliparity, oral contraceptives, medical assisted reproduction and deficiency of vitamin A are also believed to increase the risk. Some studies report that some cases of recurrent CHM were associated with 
mutations of the NLRP7 region of chromosome 19. It is also believed that metalloproteinase's and vascular endothelial growth factors are highly associated with molar pregnancies. ${ }^{6}$

\section{Signs and symptoms}

The most frequent clinical features are missed menstrual periods, vaginal bleeding (frequently with haemoglobin blood levels $<10 \mathrm{~g} / \mathrm{dL}$ ), enlarged uterus, ovarian theca lutein cysts (multilocular cysts with about $5-10 \mathrm{~cm}$ of diameter) and maternal manifestations such as hyperthyroidism, hyperemesis gravidarum or preeclampsia beginning before 20 weeks of gestation. ${ }^{2,5,7} \mathrm{CC}$ and PSTT may follow any kind of pregnancy events, even postpartum of a term pregnancy. ${ }^{1,8,9}$

The main differential diagnoses are incomplete or missed abortion and ectopic pregnancy. ${ }^{3}$

\section{Laboratorial findings}

GTD is suspected when the serum levels of B-hCG are elevated (usually more than expected for a normal or ectopic pregnancy of the same gestacional age, frequently higher than 100.000 in $\mathrm{CHM}$ ) and when characteristic ultrasound images are found.,5

\section{Ultrasound features}

CHM usually presents as a central heterogeneous mass with various anechoic spaces (hydatidiform swelling of the hydroptic chorionic villi) classically called "bunch of grapes" or "snowstorm" pattern associated with ovarian theca lutein cysts, but with no embryo, fetus or amniotic fluid (there are rare cases described in the literature with fetus)..$^{10,11}$

PHM presents as focal anechoic spaces and increased echogenicity of the chorionic villi, classically named the "Swiss cheese pattern", usually with a fetus and amniotic fluid but rarely presenting theca lutein cysts. ${ }^{12}$ When invasive, moles tend to be less well defined and have high vascular flow and myometrium invasion.

CC and PSTT usually appear as a heterogeneous high vascular mass enlarging the uterus, with areas of necrosis and haemorrhage. PSTT and ETT are usually less hemorrhagic and culminate with lower levels of B-hGC. ${ }^{13}$

\section{Histologic features}

The confirmation of the diagnosis requires histologic examination (eventually with determination of karyotipe). Tissue may be obtained either by suction curettage or hysterectomy. As all of GTD derive from human placental tissue, they may arise from the 3 types of trophoblast (syncytiotrophoblast, cytotrophoblast or intermediate trophoblast) Microscopy reveals abnormal villous or extravillous trophoblast. ${ }^{1,10}$
CHM are usually characterized by villous architecture with abnormal trophoblast hyperplasia, diffuse swelling of villi, stromal hypercellularity and collapsed villous blood vessels. They are usually diploid and androgenetic, $80 \%$ resulting from duplication of the genome of a single sperm and $20 \%$ from dispermic fertilization of an ovum, mainly $46 \mathrm{XX}$ but it can be $46 \mathrm{XY} .^{3,10,14}$

PHM show villous hydroptic changes with abnormal focal irregular villi and trophoblastic hyperplasia with pseudo inclusions. They're almost always triploid as a result of the fertilization of an ovum by 2 sperms or by a diploid sperm. ${ }^{2}$

$\mathrm{CC}$ is an epithelial tumour with villous trophoblast phenotype with central necrosis and areas with multinucleate and cytotrophoblastic-like cells and areas with pleomorphic syncitiotrophoblastic-like cells.

PSTT derives from extravillous interstitial implantation site trophoblast and histology shows monomorphic interstitial trophoblast with pleomorphism and mitosis, expressing human placental lactogen (hPL) and low BhGC. ${ }^{2,8,10}$ ETT differs from PSTT in its nested, nodular growth. ${ }^{8,13,15,16}$

\section{Staging}

About $15 \%$ of the patients with trophoblastic malignancies will have metastatic disease, especially to the lungs and vagina. CC usually spreads to the lungs, brain, liver and pelvic organs after vascular invasion. PSTT may metastise to the lungs, peritoneum, liver and brain, although it is associated with less vascular invasion and usually presents with lymphatic metastasis. ${ }^{1,8}$

FIGO has published a staging system of the trophoblastic tumours (Stage I - limited to the uterus; Stage II Invasion of only the other genital structures; Stage III disease extending to the lungs; Stage IV - all other metastatic sites) (Table 1). ${ }^{7,14,17}$

Table 1: FIGO staging of trophoblastic tumours.

\begin{tabular}{|ll|}
\hline Stage & $\begin{array}{l}\text { Description } \\
\text { I }\end{array}$ \\
\hline II & $\begin{array}{l}\text { Gestational trophoblastic tumours strictly } \\
\text { extending to the aderine corpus } \\
\text { vagina, but limited to the genital structures }\end{array}$ \\
\hline III & $\begin{array}{l}\text { Gestational trophoblastic tumours } \\
\text { extending to the lungs, with or } \\
\text { without genital tract involvement }\end{array}$ \\
\hline IV & All other metastatic sites \\
\hline
\end{tabular}

If invasive disease is suspected, investigation includes physical examination, blood count, coagulation tests, liver and renal function, pelvis ultrasound, chest X-ray, CT or MRI of the brain, chest, abdomen and pelvis. ${ }^{14}$ 


\section{Management}

Moles appear in women during their reproductive period, so the women's desire to preserve fertility is a question of major concern. Molar pregnancies are treated with suction curettage (regular curettage should be avoided due to the risk of uterine perforation). ${ }^{3}$ If childbearing has been completed, hysterectomy is an option. ${ }^{7}$ The adnexa do not need any intervention even in the presence of theca luthein cysts. ${ }^{1}$

For malignant cases or if the disease is proven to be invasive, chemotherapy is indicated, to which moles are usually very sensitive. ${ }^{14}$ Before the use of chemotherapy, invasive trophoblastic disease had quite poor prognosis and choriocarcinoma had a mortality of nearly $100 \%{ }^{1}$ For low-risk GTN, single agent chemotherapy is recommended, with either Methrotrexate (MTX) or Actinomycin D (Act-D) ${ }^{6,9,18}$ For high risk GTN, the most widely used regimens are MAC (methrotrexate, actinomycin D, and cyclophosphamide) or EMA/CO (etoposide, methrotrexate, actinomycin D, cyclophosphamide, and vincristine); the latter is considered the actual standard regimen (Table 2, 3 and 4)..$^{4,18,19}$ In refractory cases EMA/EP (EMA with etoposide and platinum (Cisplatin) ) should be used. ${ }^{14}$ As last resource, BEP, VIP or TP/TE protocols may also be used (Table 2). ${ }^{14,20}$

Table 2: Management protocol according FIGO 2012. ${ }^{14}$

\begin{tabular}{|ll|}
\hline Low-risk GTN & \\
\hline Single agent & MTX (or ACT-D) \\
\hline High-risk GTN & \\
\hline Standard treatment & EMA-CO \\
\hline Resistant cases & EMA-EP (or BEP) \\
\hline
\end{tabular}

Table 3: Management protocol according to the clinical stage.

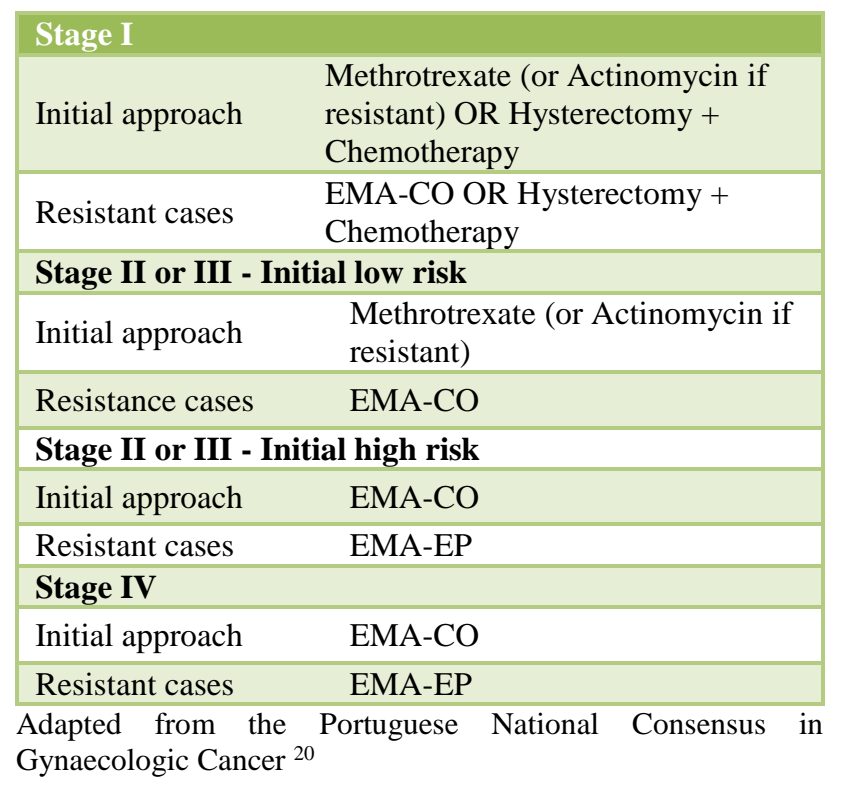

PSTT is highly resistant to chemotherapy so the recommended protocol is EMA/CO or EMA/EP though there are still few studies on the subject due to the low frequency of the disease..$^{8,14,18,20,21}$ There is no consensus on the ideal duration of the chemotherapy, some suggest keeping treatment until B-hCG levels become normal, others suggest keeping for 2 additional cycles. ${ }^{22}$ Prophylaxis with anti-D globulin must be performed in Rh-negative women. ${ }^{3}$ In cases with metastatic persistent disease to the lungs or liver after chemotherapy, surgical resection of the nodules may be an option. Radiotherapy and higher doses of Methrotrexate may be indicated if there are brain metastases. ${ }^{14,20}$

\section{Prognosis}

Most cases of complete or partial moles resolve completely after therapy, but about $15 \%$ and $5 \%$ of the cases respectively are persistent or malignant. ${ }^{1} \mathrm{WHO}$ has proposed a prognostic scoring system for GTN based on risk factors, aiming to defined cases with high risk of persistent or malignant disease, based on 8 criteria: age of patient, obstetric history, time since last GTD or pregnancy, serum levels of B-hGC, diameter of tumour, number and location of metastasis and previous chemotherapy (Table 5 ). ${ }^{14,16}$ Medical complications such as preeclampsia or hyperthyroidism and higher size of lutein cyst are also considered risk factors for persistent disease. This score may also be useful to define the adequate treatment.

The overall rates of cure of GTN are estimated to be around $98 \% .^{23}$ The rates of survival of low-risk patients treated with monotherapy are around $100 \%$ while highrisk patients after polychemotherapy are $87 \% .{ }^{24}$ PSTT is usually confined to the uterus, but considering its characteristic resistance to chemotherapy there are few long-term survivors with disease PSTT. ${ }^{8}$

\section{Follow-up}

Serial control of B-hGC levels after treatment must be performed in all cases in order to evaluate the cure or the persistence of reminiscent disease. There are numerous protocols for the follow-up of these patients. One option is the weekly measurement of B-hCG. When complete remission is achieved (which is defined as 3 negative results), monthly measurements must be performed during one year with negative results. Stage IV diseases must be followed for more 24 months. ${ }^{20}$ Effective contraception is required during this period to avoid mistakes with new pregnancies.

More than half of the patients reach normal and persistent B-hCG levels 2 months after evacuation. ${ }^{1}$ The risk of recurrence after 1 year of remission is less than $1 \% .{ }^{5}$ FIGO proposed some criteria for suspicion of persistent disease based on B-hGC levels: levels that plateau, rises or declines less than $10 \%$ in 4 evaluations over three weeks, or levels that remain detectable for 
more than 6 months. In most cases (about 90\%), persistent high levels correspond to invasive moles, except after nonmolar pregnancies, which persistent levels of B-hGC are always due to choriocarcinoma or PSTT.
There is no evidence that patients with GTN after chemotherapy have an adverse pregnancy outcome. It's recommended an early ultrasound in order to exclude a new molar pregnancy. ${ }^{22}$

Table 4: Therapeutic protocols recommend in GTN. ${ }^{14,20}$

\begin{tabular}{|c|c|c|c|c|c|}
\hline Protocol & Drug & Doses & $\begin{array}{l}\text { Administration } \\
\text { route }\end{array}$ & $\begin{array}{l}\text { Day of } \\
\text { administration }\end{array}$ & $\begin{array}{l}\text { Rhythm of } \\
\text { administration }\end{array}$ \\
\hline \multirow[t]{3}{*}{ Methrotrexate } & Methrotrexate & $0.4 \mathrm{mg} / \mathrm{Kg}$ & IM & $\mathrm{D} 1,2,3,4,5$ & Each 14 days \\
\hline & Methrotrexate & $50 \mathrm{mg} / \mathrm{Kg}$ & IM & D1 & Each 7 days \\
\hline & Methrotrexate & $250 \mathrm{mg}$ & 12h IV infusion & & Each 14 days \\
\hline \multirow{2}{*}{$\begin{array}{l}\text { Methrotrexate + } \\
\text { Leucovorin }\end{array}$} & Methrotrexate & $1 \mathrm{mg} / \mathrm{Kg}$ & IM & D1, D3, D5, D7 & \multirow{2}{*}{ Each 14 days } \\
\hline & Leucovorin & $0.1 \mathrm{mg} / \mathrm{Kg}$ & IM & D2, D4, D6, D8 & \\
\hline \multirow[t]{3}{*}{ Actinomycin -D } & Actinomycin -D & $1.25 \mathrm{mg} / \mathrm{m}^{2}$ & IV & D1 & Each 14 days \\
\hline & Actinomycin -D & $12 \mathrm{ug} / \mathrm{Kg}$ & IV & D1 & Each 14 days \\
\hline & Actinomycin -D & $0.5 \mathrm{mg}$ & IV & $\mathrm{D} 1,2,3,4,5$ & Each 14 days \\
\hline \multirow[t]{7}{*}{ EMA-CO } & Etoposide & $100 \mathrm{mg} / \mathrm{m}^{2}$ & IV & D1, D2 & \multirow[t]{7}{*}{ Each 14 days } \\
\hline & Methrotrexate & $100 \mathrm{mg}$ & IV & D1 & \\
\hline & & $200 \mathrm{mg} / \mathrm{m}^{2}$ & $\begin{array}{l}12 \mathrm{~h} \mathrm{IV} \\
\text { Perfusion }\end{array}$ & & \\
\hline & Leucovorin & $15 \mathrm{mg}$ & IV & $\begin{array}{l}\text { D2 - } 8 \text { doses } \\
(6 / 6 h)\end{array}$ & \\
\hline & Actinomycin -D & $0,5 \mathrm{mg}$ & IV & $\mathrm{D} 1, \mathrm{D} 2$ & \\
\hline & Cyclophosphamide & $600 \mathrm{mg} / \mathrm{m}^{2}$ & IV & D8 & \\
\hline & Vincristine & $1 \mathrm{mg} / \mathrm{m}^{2}$ & IV & D8 & \\
\hline \multirow[t]{5}{*}{ EMA-EP } & Etoposide & $100 \mathrm{mg} / \mathrm{m}^{2}$ & IV & D1, D2, D8 & \multirow[t]{5}{*}{ Each 14 days } \\
\hline & Methrotrexate & $100 \mathrm{mg}$ & IV & D1, D8 & \\
\hline & & $200 \mathrm{mg} / \mathrm{m}^{2}$ & Perfusion & & \\
\hline & Actinomycin -D & $0,5 \mathrm{mg}$ & IV & D1, D2, D8 & \\
\hline & Cisplatine & $80 \mathrm{mg} / \mathrm{Kg}$ & IV & D1 & \\
\hline \multirow[t]{4}{*}{ MAC } & Methrotrexate & $1 \mathrm{mg} / \mathrm{Kg}$ & IM & $\mathrm{D} 1,3,5,7$ & \multirow[t]{4}{*}{ Each 14 days } \\
\hline & Actinomycin -D & $12 \mathrm{ug} / \mathrm{Kg}$ & IV & $\mathrm{D} 1,2,3,4,5$ & \\
\hline & Cyclophosphamide & $3 \mathrm{mg} / \mathrm{Kg}$ & IV & $\mathrm{D} 1,2,3,4,5$ & \\
\hline & Leucovorin & $0,1 \mathrm{mg} / \mathrm{Kg}$ & IV & $\mathrm{D} 2,4,6,8$ & \\
\hline \multirow[t]{5}{*}{ BEP } & Bleomycin & $10 \mathrm{U} / \mathrm{m}^{2} / \mathrm{d}$ & 96h IV infusion & $\mathrm{D} 2,3,4$ & \multirow[t]{5}{*}{ Each 21 days } \\
\hline & Etoposide & $100 \mathrm{mg} / \mathrm{m}^{2}$ & IV & $\mathrm{D} 1,2,3,4$ & \\
\hline & Cisplatine & $100 \mathrm{mg} / \mathrm{m}^{2}$ & IV & D1 & \\
\hline & Cisplatine & $60 \mathrm{mg} / \mathrm{m}^{2}$ & IV & D1 & \\
\hline & Etoposide & $150 \mathrm{mg} / \mathrm{m}^{2}$ & IV & D15 & \\
\hline
\end{tabular}

Table 5: FIGO/WHO scoring system based on risk factors.

\begin{tabular}{|lllll|}
\hline Score & 0 & 1 & 2 & 4 \\
\hline Age & $<40$ & $\geq 40$ & - & - \\
\hline Previous pregnancy & Mole & Abortion & Viable Pregnancy & - \\
\hline Months from previous pregnancy & $<4$ & $4-6$ & $7-12$ & $>12$ \\
\hline Pre-treatment B-hCG levels & $<10^{3}$ & $10^{3}-10^{4}$ & $10^{4}-10^{5}$ & $>10^{5}$ \\
\hline Largest tumour size & - & $3-4$ & $\geq 5$ & - \\
\hline Site of metastasis & Lung & Spleen, Kidney & Gastrointestinal tract & Brain, Liver \\
\hline Number of metastasis & - & $1-4$ & $5-8$ & $>8$ \\
\hline Previous failed chemotherapy & - & - & Single agent & Multi agent \\
\hline
\end{tabular}




\section{CASE REPORT}

4 cases were identified - 2 invasive complete and 1 partial hydatidiform moles and 1 placental site trophoblastic tumour.

\section{Case 1}

Metastatic and persistent complete hydatidiform mole

A 21 years old, primigravidae, previously medicated with cyproterone ethinyl estradiol $2 / 0.035$ combined pill with no pathological relevant history, presented with unusual vaginal bleeding. There were no other abnormal findings at physical examination.

At transvaginal ultrasound scan there was an endometrial thickening apparently invading the myometrium and teca luthein cysts on the right ovary (Figure 1 and 2). B-hCG levels were $632.412 \mathrm{mIU} / \mathrm{mL}$.

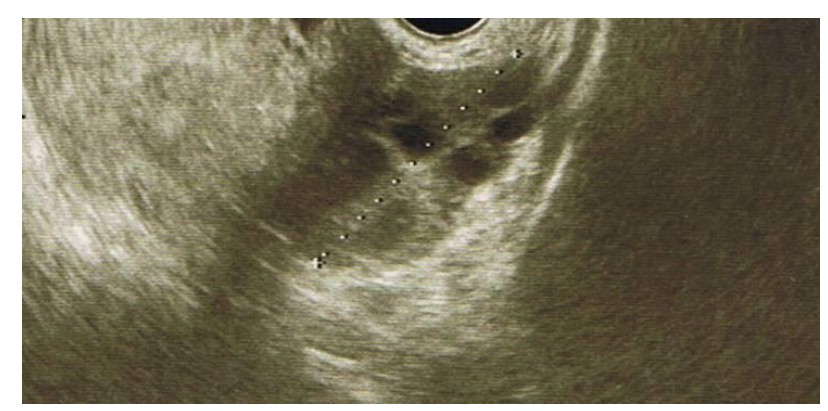

Figure 1: Teca luthein cyst at transvaginal ultrasound.

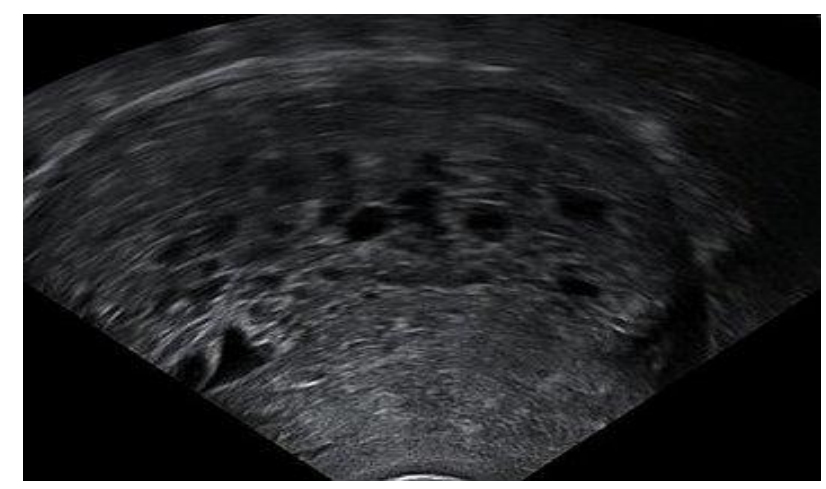

Figure 2: Transvaginal ultrasound at admission.

She was submitted to uterine suction curettage. Microscopic examination revealed complete hydatidiform mole. B-hCG serum levels were checked every 2-3 days reaching a minimum value of $22.162 \mathrm{mIU} / \mathrm{mL}$ nine days after uterine evacuation, but at ultrasound evaluation there were signs of persistent disease at the uterine fundus, adherent to the uterine wall. Chest CT-scan showed 2 nodules at the right lung suggestive of metastatic lesions (Figure 3) but brain MRI was normal. Abdominal and pelvic MRI one month after uterine curettage showed an irregular, round-shape image, $3 \mathrm{~cm}$ mass at the uterine fundus. The patient was classified as stage III A (initial low-risk) according to FIGO score.

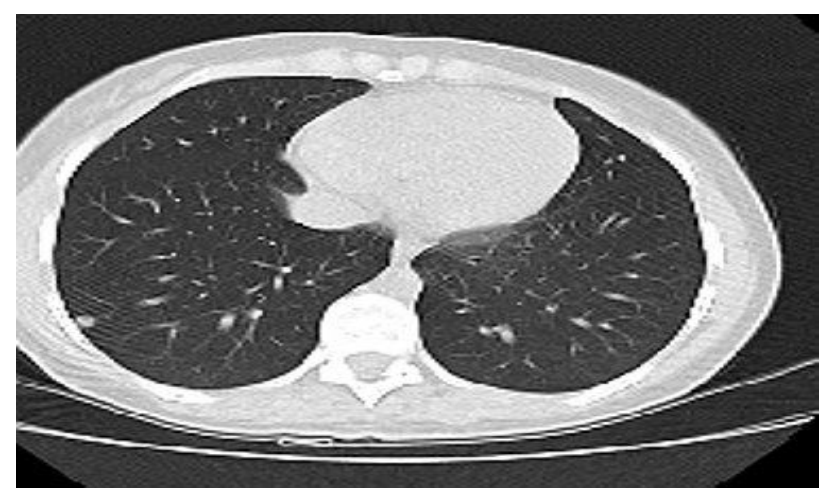

Figure 3: Lung metastasis at CT.

The patient was treated with mono-chemotherapy with methotrexate. Patient has been followed from that time on, with serialserum B-hGC measurements, she had a full imagiologic, clinical and analytic recovery and remained disease free for 1 year after reaching negative serum BhGC levels.

\section{Case 2}

\section{Metastatic partial hydatidiform mole}

A 24 years old, with one previous first trimester miscarriage 15 months before, with no other pathologic relevant past data, was suspected to have a molar pregnancy at first trimester obstetric ultrasound, as an incidental finding. The patient was asymptomatic. Despite a subtly enlarged uterus, there were no findings at physical examination. Ultrasound scan showed uterine cavity filled with a heterogeneous highly vascular mass, variably sized anechoic cysts with intervening hyperechoic material (Figure 4).

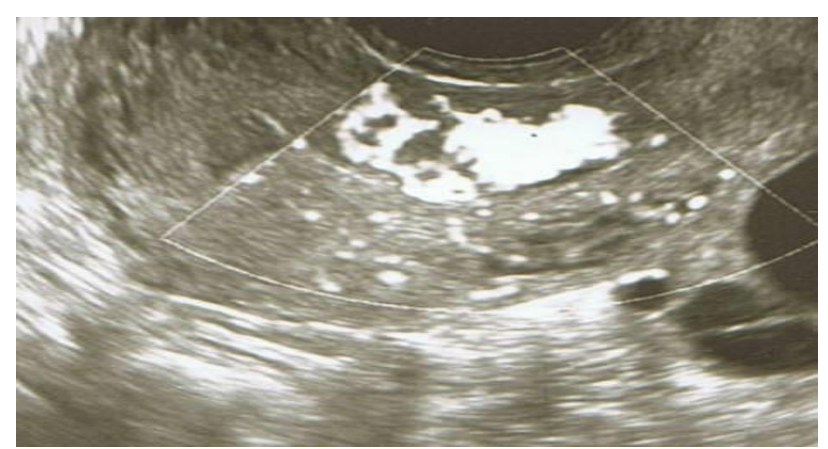

Figure 4: Highly vascular uterine mass at transvaginal ultrasound.

B-hCG serum levels were $342.352 \mathrm{mIU} / \mathrm{mL}$. She was submitted to uterine suction curettage. Microscopic examination revealed Partial Hydatidiform Mole. After uterine evacuation the patient kept diminishing values of B-hCG until 3 weeks after the procedure when values 
began to rise (minimum value of $3916 \mathrm{mIU} / \mathrm{mL}$ ). Abdominal and pelvic MRI showed empty uterine cavity but also an infiltrative mass invading the myometrium (Figure 5), Chest CT-scan revealed various lung metastatic lesions, the biggest one with $18 \mathrm{~mm}$. Brain MRI was normal.

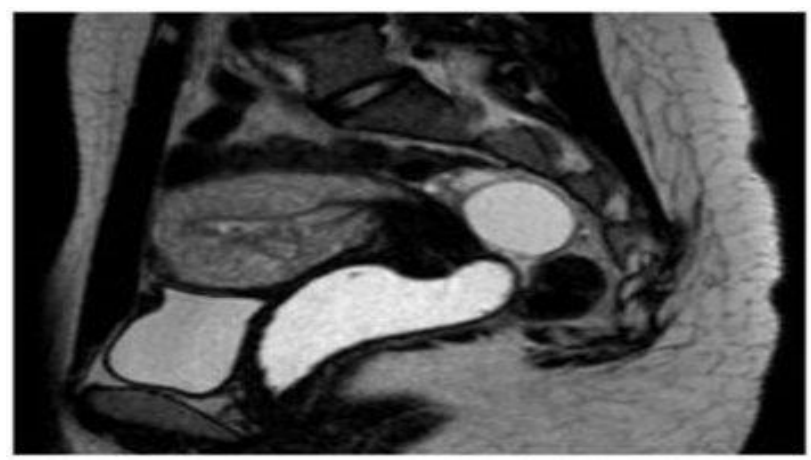

Figure 5: Uterine mass at MRI.

The patient was classified as stage III B (initial high-risk) according to FIGO score. She was treated with polychemotherapy according to EMA-CO protocol. Follow-up was carried out with serial serum B-hCG measurements. She had a full imagiologic, clinical and analytic recovery and remained disease free.

She had a following normal pregnancy with no occurrences and a term vaginal delivery.

\section{Case 3}

\section{Invasive complete hydatidiform mole}

A 52 years old woman, with 2 previous term vaginal deliveries and one spontaneous miscarriage presented with abnormal vaginal bleeding after 2 months of amenorrhea. At physical examination there was only abnormal uterine bleeding. At the ultrasound scan there was a heterogeneous endometrial thickening of $23 \mathrm{~mm}$. B-hCG serum levels were $23.744 \mathrm{mIU} / \mathrm{mL}$. Chest, abdominal and pelvic CT-scan and brain MRI showed no metastatic or remaining lesions.

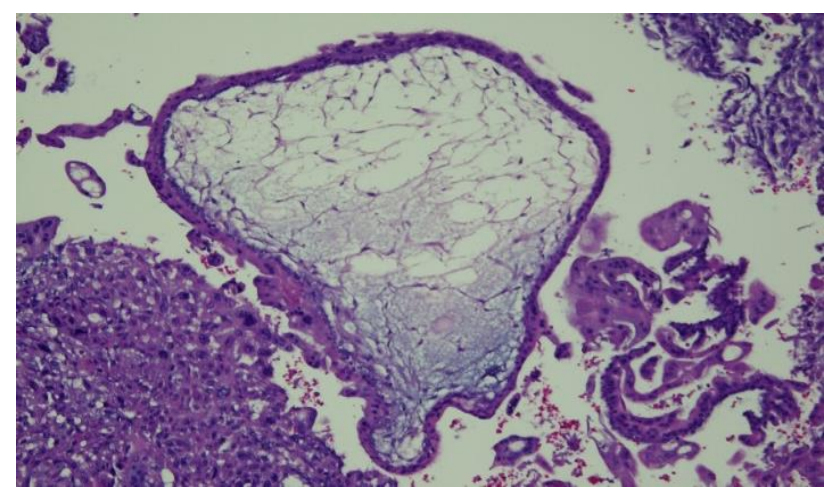

Figure 6: Proliferating chorionic villi invading the myometrium.

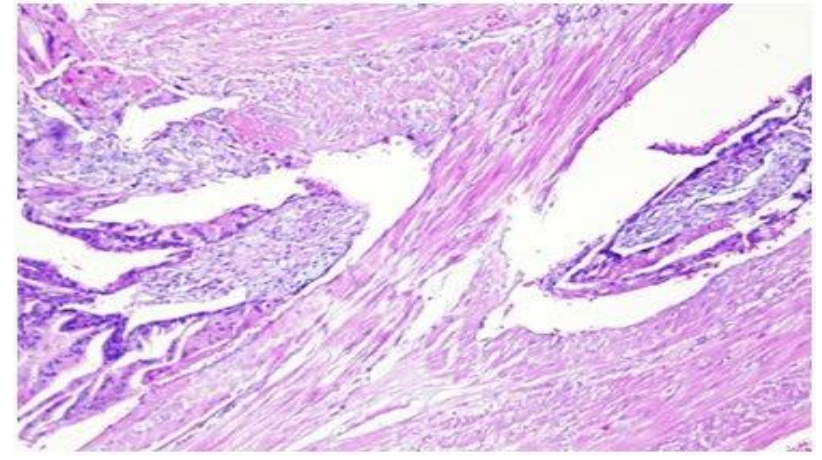

Figure 7: Proliferating chorionic villi invading the myometrium.

As there was strong evidence of hydatidiform mole and taking into account the patient's age, she was submitted to total abdominal hysterectomy and bilateral ooforectomy. Microscopic examination revealed complete invasive hydatidiform mole (Figure 6 and 7). The patient was classified as stage I according to FIGO score. One year after reaching negative serum B-hCG levels, the patient remained disease free, with negative serum B-hCG.

\section{Case 4}

\section{Placental Site trophoblastic tumour}

A 49 years old woman, with 2 previous term vaginal deliveries and no pathologic relevant features, was suspected to have a molar pregnancy at ultrasound scan. Despite the amenorrhea of 8 weeks she was asymptomatic and presented a normal physical examination. The ultrasound scan revealed a heterogeneous highly irrigated mass invading the myometrium. B-hCG serum levels were 122.168 $\mathrm{mIU} / \mathrm{mL}$. She was submitted to uterine evacuation by suction. The microscopic examination was suggestive of molar pregnancy.

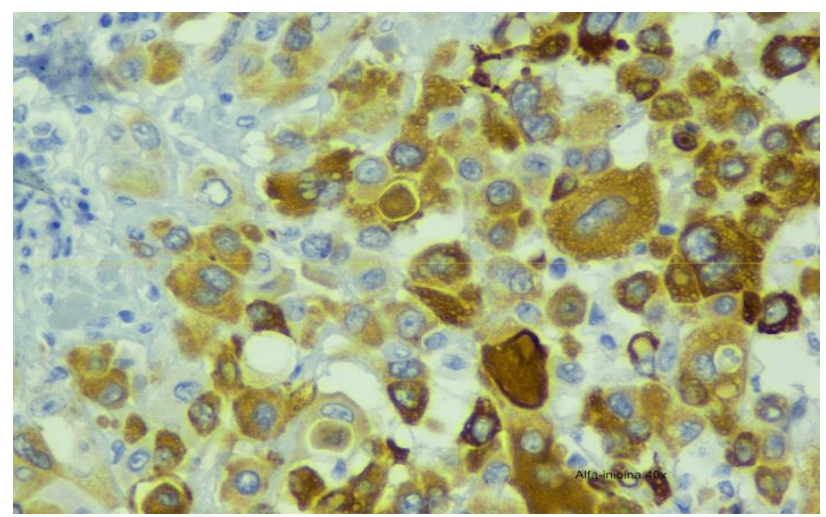

Figure 8: Proliferating extra villous tissue, positive to alfa inhibin.

B-hCG progressively decreased reaching normal values 6 months later when they began to modestly rise again. At 
that time, CT-scan was performed showing a $2 \mathrm{~cm}$ mass at the uterine fundus.

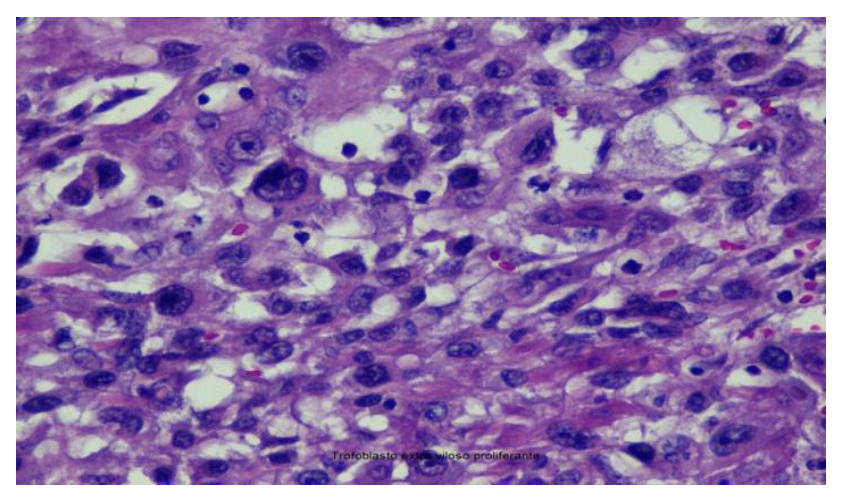

Figure 9: Proliferating extra villous tissue, positive to alfa inhibin.

Due to the patient's age, she was submitted to total hysterectomy and bilateral ooforectomy through laparotomy. Microscopic examination of the surgical specimen came out as placental site trophoblastic tumour (Highly proliferating extra villous tissue, positive to alfa inhibin) (Figure 8 and 9). She underwent chemotherapy according to EMA-CO protocol. During the whole follow-up of the patient there were no radiologic findings suggestive of metastatic lesions. The patient remained disease free, 2 years later.

\section{DISCUSSION}

As expected, all patients were at the reproductive age, two of them near menopause. Our patients were either asymptomatic or presented with abnormal vaginal bleeding, which is the most common manifestation of GTD, along with amenorrhea. As expected, all of the patients had high values of $\mathrm{B}-\mathrm{hCG}$ at the time of diagnosis; only one patient had values less than 100.000 . Heterogeneous endometrial thickening at ultrasound was present in all cases. Our patient with PSTT had unexpected high B-hCG levels for this kind of tumours.

Sequential control of B-hCG levels after primary treatment is mandatory to exclude persistence of disease. The Portuguese Gynaecology Society's protocol recommends weekly measurement of B-hCG, until full remission is achieved (which is defined as 3 negative results), monthly additional measurement follows during one year. FIGO Stage IV diseases (metastatic disease other than genital tract or lungs) must be followed for more 24 months. ${ }^{20}$

As $15 \%$ of the patients with trophoblastic malignancies will have metastasis or persistent, this must always be excluded. The first manifestation of persistent disease was elevation of B-hCG serum levels in three of the cases and metastatic disease in the other one. Three patients had macroscopic or imagiologic evidence of invasion of the myometrium and two patients had evidence of metastatic disease, both to the lungs only. Moles appear in women during their reproductive period, so women's desire to preserve fertility is a question of major concern. In our four cases we had different approaches; we opted for hysterectomy in older patients and a more conservative attitude (uterine suction curettage and chemotherapy) in patients who wanted to preserve fertility. The PSTT patient was initially managed with uterine curettage but afterwards was submitted to hysterectomy as well, when the diagnosis was confirmed as this is the ideal approach to this pathology.

In our cases, individualized chemotherapy was highly effective, including those patients with metastatic disease and in PSTT so far. No recurrence was diagnosed during follow-up. One of the patients had a following normal pregnancy with no occurrences and had a term vaginal delivery. Although a previous molar pregnancy is one of the main risk factors to have another molar pregnancy, none of the 2 cases in which a conservative treatment was performed had previous moles or developed afterwards.

\section{CONCLUSION}

This case series highlights the importance of an early and accurate diagnosis of hydatidiform moles, particularly the importance of a long-term follow-up considering the risk of persistent or malignant disease, as GTN is a group of malignant entities that have a good response to adequate therapy.

Malignancy must always be kept in mind in presence of GTD. All women with GTD must be followed with serial serum B-hCG measurements until negative values have been reached in order to exclude malignant disease. All pregnancies after GTD must be studied carefully due to higher risk of other molar pregnancy.

Funding: No funding sources

Conflict of interest: None declared

Ethical approval: Not required

\section{REFERENCES}

1. Lurain JR. Gestational trophoblastic disease I: epidemiology, pathology, clinical presentation and diagnosis of gestational trophoblastic disease, and management of hydatidiform mole. Am J Obstet Gynecol. 2010;203:531-9.

2. Seckl MJ, Sebire NJ, Berkowitz RS. Gestational trophoblastic disease. Lancet. 2010;376:717-29.

3. de Andrade JM. Mola hidatiforme e doença trofoblástica gestacional. Rev Bras Ginecol Obs. 2009;31:94-101.

4. Froeling FEM, Seckl MJ. Gestational trophoblastic tumours: an update for 2014. Curr Oncol Rep. 2014;16:408.

5. Monchek R, Wiedaseck S. Gestational trophoblastic disease: an overview. J Midwifery Womens Health. 2012;57:255-9. 
6. Berkowitz RS, Goldstein DP. Current advances in the management of gestational trophoblastic disease. Gynecol Oncol. 2013;128:3-5.

7. American Cancer Society. Gestational Trophoblastic Disease. 2014. Available at: http://www.cancer.org/cancer/gestationaltrophoblasti cdisease/. Accessed 1 October 2016.

8. Kim SJ. Placental site trophoblastic tumour. Best Pract Res Clin Obstet Gynaecol. 2003;17:969-84.

9. National Cancer Institute. Gestational Trophoblastic Disease - For Health Professionals. 2015. Available at: https://www.cancer.gov/types/gestationaltrophoblastic/hp/gtd-treatment-pdq. Accessed 1 October 2016.

10. Cheung AN-Y. Pathology of gestational trophoblastic diseases. Best Pract Res Clin Obstet Gynaecol. 2003;17:849-68.

11. Rohilla M, Singh P, Kaur J, Jain V, Gupta N, Prasad GR V. Individualistic approach to the management of complete hydatidiform mole with coexisting live fetus. Eur J Obstet Gynecol Reprod Biol. 2015;191:39-42.

12. Allias F, Bolze P-A, Gaillot-Durand L, Devouassoux-Shisheboran M. Gestational trophoblastic disease. Ann Pathol. 2014;34:434-47.

13. Davis MR, Howitt BE, Quade BJ, Crum CP, Horowitz NS, Goldstein DP, et al. Epithelioid trophoblastic tumor: A single institution case series at the New England Trophoblastic Disease Center. Gynecol Oncol. 2015;137:456-61.

14. Ngan HYS, Kohorn EI, Cole LA, Kurman RJ, Kim SJ, Lurain JR, et al. Trophoblastic disease. Int J Gynaecol Obstet. 2012;119:S130-6.

15. Allison KH, Love JE, Garcia RL. Epithelioid trophoblastic tumor: review of a rare neoplasm of the chorionic-type intermediate trophoblast. Arch Pathol Lab Med. 2006;130:1875-7.

16. Palmer JE, Macdonald M, Wells M, Hancock BW, Tidy JA. Epithelioid trophoblastic tumor: a review of the literature. J Reprod Med. 2008;53:465-75.

17. Prat J, Belhadj H, Berek J, Bermudez A, Bhatla N,
Cain J, et al. Abridged republication of FIGO's staging classification for cancer of the ovary, fallopian tube, and peritoneum. Eur J Gynaecol Oncol. 2015;36:367-9.

18. Gerulath AH, Ehlen TG, Bessette P, Jolicoeur L, Savoie R. Gestational trophoblastic disease. J Obstet Gynaecol Cana. 2002;24:434-46.

19. Deng L, Zhang J, Wu T, Lawrie TA. Combination chemotherapy for primary treatment of high-risk gestational trophoblastic tumour. Cochrane database Syst Rev. 2013;1:CD005196.

20. Sociedade Portuguesa de Ginecologia; Sociedade Portuguesa de Oncologia; Sociedade Portuguesa de Radiologia Oncológica; Sociedade Portuguesa de Anatomia Patológica. Consenso - Cancro Ginecológico. 2013. Available at: http://www.spginecologia.pt/notcias-daspg/consenso-cancro-ginecologico-consensosnacionais-2013.html. Accessed 1 October 2016.

21. Turan T, Karacay O, Tulunay G, Boran N, Koc S, Bozok S, et al. Results with EMA/CO (etoposide, methotrexate, actinomycin D, cyclophosphamide, vincristine) chemotherapy in gestational trophoblastic neoplasia. Int $\mathbf{J}$ Gynecol Cancer. 2006;16:1432-8.

22. Ng TY, Wong LC. Diagnosis and management of gestational trophoblastic neoplasia. Best Pract Res Clin Obstet Gynaecol. 2003;17:893-903.

23. Seckl MJ, Sebire NJ, Fisher RA, Golfier F, Massuger L, Sessa C. Gestational trophoblastic disease: ESMO Clinical Practice Guidelines for diagnosis, treatment and follow-up. Ann Oncol. 2013;24 (Suppl 6):vi3950 .

24. Noal S, Joly F, Leblanc E. Management of gestational trophoblastic disease. Gynécologie, Obs Fertil. 2010;38:193-8.

Cite this article as: Brandão P, Silva-Rocha J, Pinto AR, Costa F. Distinct gestational trophoblastic neoplasia - different entities, specific management. Int J Reprod Contracept Obstet Gynecol 2017;6:74956. 